Going to Work: the Provincial

\title{
Mãos à obra: o governo provincial paraense e seus esforços para a navegação da região amazônica - 1850-1867
}

Government of Grão-Pará and

its efforts for the Amazonian

Navigation - 1850-1867

\author{
Vitor Marcos Gregório \\ Mestre em História pela Universi- \\ dade de São Paulo \\ e-mail: vitorgregorio@usp.br
}

\section{Resumo}

Este artigo tem por objetivo divulgar alguns resultados da pesquisa intitulada Uma face de Jano: a navegação do rio Amazonas e a formação do Estado brasileiro (1838-1867), realizada a nível de mestrado, e defendida em 2008. Trata especificamente dos esforços realizados pelo governo provincial paraense para a realização da navegação a vapor nos rios amazônicos localizados em seu território, em complemento às medidas tomadas a nível central. Com isto, pretende indicar que os governos provinciais possuíam relativa autonomia em seu trato com o poder central, ao menos no que respeita ao atendimento das demandas que consideravam fundamentais para o desenvolvimento da região sob sua jurisdição.

\begin{abstract}
This paper presents some research results of the dissertation named $A$ face of Jano: the navigation of the Amazon river and the brazilian State formation, presented in 2008. It analyzes, more specifically, the efforts made by the provincial government of Grão-Pará to enable the steam navigation of amazonian rivers located in its territory, in addition to discussing the measures taken by the central sphere of power. By doing so, it intends to indicate that the provincial governments had a relative autonomy in its relations with the central power, at least regarding to its ability to address the demands they considered fundamental to the development of the region under its jurisdiction.
\end{abstract}

\section{Palavras-chave}

Amazônia, Grão-Pará, poder legislativo, práticas políticas, política / administração

\section{Keywords}

Amazônia, Grão-Pará, legislative power, political practices, politics / administration 
Para mais detalhes sobre a existência de um regime de tipo federativo no Brasil imperial, ver DOLHNIKOFF, Miriam. O pacto imperial: origens do federalismo no Brasil. São Paulo: Globo, 2005.

Esta questão, entretanto, ainda não foi completamente abandonada pelo autor, que pretende voltar a ela através da análise de outras fontes documentais em pesquisa posterior.

3

Importante lembrar aqui que, para os presidentes das províncias amazônicas, a principal atividade econômica da região era a agricultura, única capaz de levar a civilização e o desenvolvimento àquelas paragens. Neste sentido o extrativismo, embora fornecedor de lucros crescentes principalmente a partir da década de 1850 - graças em grande medida ao aumento do valor da borracha no mercado internacional -, sempre foi visto como uma atividade marginal, nociva aos interesses provinciais na medida em que desviava da lavoura os parcos recursos humanos então existentes. Sobre isto, ver PEREIRA, Nasthya Cristina Garcia. Relações homem-natureza: o discurso político sobre agricultura e extrativismo na Provincia do Amazonas (1852-1889). 2008. 145f. Dissertação (Mestrado em História). Instituto de Ciências Humanas e Letras, Universidade Federal do Amazonas, Manaus, 2008.
A partir de 1850 o governo imperial brasileiro se engajaria fortemente nos esforços para navegação do rio Amazonas. A elaboração da lei n 586 consagrava ao poder Executivo todos os meios necessários para a introdução de linhas de vapores no rio, e o contrato assinado com Irineu Evangelista de Souza em 1852 seria uma conseqüência desta medida. Ao governo provincial do Grão-Pará, entretanto, não bastavam as políticas adotadas pela Corte. Desde a década de 1830 os administradores da província enfrentavam o problema da dificuldade de comunicação com os pontos mais distantes de seu território da forma que lhes era possivel. E continuariam a se preocupar com esta questão mesmo após o início das atividades da Companhia de Navegação e Comércio do rio Amazonas, uma vez que ainda permaneceria a necessidade de prestação deste serviço de modo mais conforme aos interesses e necessidades imediatos da administração paraense.

Este artigo busca analisar as tentativas do governo provincial no sentido de implementar políticas que permitissem a realização deste objetivo. Desta forma, pretende oferecer elementos que permitam repensar a relação existente entre o centro e as periferias no regime político brasileiro de meados do século XIX, através da demonstração de que, ao menos no que tange ao caso do Grão-Pará, existia nesta época uma importante margem de manobra que garantia às elites regionais meios para atender algumas de suas demandas mais urgentes. ${ }^{1}$ A navegação a vapor nos rios amazônicos encaixava-se bem nesta definição, razão pela qual foi o objeto escolhido para a realização deste exercício.

Como documentação principal foi escolhido o conjunto de relatórios da presidência da província do Grão-Pará durante o período estudado, por constituir uma fonte privilegiada de informações sobre a atuação desta esfera de poder no periodo imperial. Os anais da Assembléia Legislativa provincial também seriam de grande importância para este trabalho, uma vez que nos permitiriam visualizar os debates ocorridos em torno dos projetos aqui tratados, demonstrando quais seriam os grupos políticoeconômicos que ganhariam e quais perderiam com as medidas discutidas e, posteriormente, adotadas. Da mesma forma, nos apresentariam projetos alternativos aos que sairam da arena legislativa provincial como vencedores, permitindo uma análise mais ampla sobre representatividade e tomada de decisões nesta esfera de poder. Entretanto, durante a pesquisa nos arquivos e bibliotecas da capital paraense, foi constatada a impossibilidade de consulta a este material. Este fato se deve a um incêndio ocorrido no prédio da Assembléia Legislativa paraense, o qual consumiu em sua totalidade os anais relativos ao período coberto por este texto. ${ }^{2}$

\section{Preocupações da administração paraense em meados do século XIX}

Ao amanhecer da década de 1850, uma das principais preocupações dos administradores paraenses era a fundação e manutenção de colônias de povoamento. De fato, a falta de mão de obra para a realização das principais atividades econômicas da província ${ }^{3}$ foi desde sempre uma das principais reclamações dos políticos que assumiam a presidência da província, e a adoção de medidas para remediar este mal sempre esteve na ordem do dia de seus governos.

Neste sentido, em seu relatório entregue ao vice-presidente em exercício, o presidente Jerônimo Francisco Coelho descreveu com pormenores sua tentativa de fundação de uma colônia nas margens do rio Tocantins, 
Relatório feito pelo Exmo. Sr. Conselheiro Jerônimo Francisco Coelho, presidente desta província, e entregue ao $1^{\circ}$ vice presidente em exercício, o Exmo. Sr. Dr. Ângelo Custódio Corrêa, no dia $1^{\circ}$ de agosto de 1850, p.17-20. Todos os relatórios e falas do presidente de província citados neste artigo foram consultados em http://www.crl.edu/content/brazil/para.htm. Acesso em 9 de março de 2009.

5

Ibidem, p.20-22.

Relatório do presidente da provincia do GrãoPará, o Exmo. Sr. Dr. Fausto Augusto de Aguiar, na abertura da segunda sessão ordinária da sétima legislatura da Assembléia Provincial, no dia 15 de agosto de 1851, p.59-62.

7

De acordo com esta lei, o governo central ficava habilitado para incentivar a navegação a vapor do rio Amazonas mediante oferecimento de subsídios financeiros a quem se interessasse pela atividade. seguindo as determinações do governo central, sem lograr o êxito que esperava alcançar apesar de todo seu empenho na realização da tarefa.

Para seu desespero, ao início promissor das atividades da colônia de Santa Tereza do Tocantins, em outubro de 1849, seguiram-se duas epidemias que causaram a morte de vários colonos, obrigando ao abandono do sítio originalmente escolhido. Dos sobreviventes, dois grupos foram formados: um destinado a fundar outra colônia, denominada São João do Araguaia, e o outro com o objetivo de repovoar a então decadente colônia Pedro II, estratégica por encontrar-se nas proximidades de fronteiras externas do Império. Para além destas providências, o presidente referiu a tomada de medidas para a fundação de uma terceira colônia na província, que deveria se localizar na região do alto Rio Branco, missão esta deixada a cargo do comandante militar da comarca do Rio Negro. ${ }^{4}$ Além disso, estava prevista também a fundação de dois presídios militares nas margens do rio Araguaia, na divisa com a província de Goiás. 0 presidente paraense repassava a notícia com entusiasmo, pois os presídios facilitariam a comunicação entre as duas províncias, dificultada até o momento exatamente pela falta de portos intermediários no caminho. ${ }^{5}$

A fundação de colônias e presídios militares na província do GrãoPará, aliás, respondia fundamentalmente a dois objetivos: auxiliar no povoamento de regiões afastadas, garantindo o fornecimento da mão de obra necessária para seu desenvolvimento econômico, e facilitar a comunicação por via fluvial através do estabelecimento de grupamentos militares destinados a servir de pontos de descanso e proteção aos viajantes, e de fonte de carvão vegetal para as caldeiras dos vapores. Neste sentido, constituía-se em medida complementar ao estabelecimento de linhas regulares de navegação, apresentado como a política mais eficiente para, a um só tempo, possibilitar o melhoramento das comunicações no interior da província, e sua efetiva incorporação ao conjunto econômico do Império e do comércio internacional.

Desta forma pode-se entender mais facilmente os esforços provinciais para repovoar a colônia Pedro II - inclusive com o engajamento de mais militares e distribuição de terras, além de instruções para o cultivo de gêneros alimentícios - e para fundar a colônia São João do Araguaia destinada a proteger a navegação dos rios Tocantins e Araguaia, obstar as incursões indígenas e as fugas de escravos. ${ }^{6}$ Garantir o sucesso das colônias localizadas na província significava, em última instância, elevar esta região a um grau de desenvolvimento e civilização que a faria rivalizar com os pontos mais prósperos do Império. Ainda que, visto em retrospectiva, estas medidas tenham alcançado muito pouco êxito, são bastante ilustrativas do ideal de desenvolvimento que os administradores centrais e provinciais tinham para a região amazônica.

0 incentivo direto à navegação fluvial também mereceu atenção especial do governo provincial nesta época. Assim, foi com entusiasmo que o presidente Fausto Augusto de Aguiar noticiou à Assembléia Provincial, em 1851, que graças à lei no 586 , promulgada em setembro do ano anterior7, já teria se iniciado a concorrência para o estabelecimento de linhas de barcos a vapor no rio Amazonas, inclusive com a participação de um negociante paraense que, pelo tom do documento, contava com ampla simpatia da presidência:

0 distinto Paraense João Augusto Corrêa, negociante desta praça, propôs-se a tomá-la [a navegação do Amazonas], e apresentou-me suas condições, as quais levei ao conhecimento do Governo; mas tendo concorrido outros empresários, nada 
Relatório do presidente da província do GrãoPará, o Exmo. Sr. Dr. Fausto Augusto de Aguiar, na abertura da segunda sessão ordinária da sétima legislatura da Assembléia Provincial, no dia 15 de agosto de 1851, p.64-65.

9

Ibidem, p.66-67.

10

Fala que o Exmo. Sr. Dr. José Joaquim da Cunha, presidente desta provincia, dirigiu a Assembléia Legislativa Provincial, na abertura da mesma assembléia, no dia 15 de agosto de 1853, p.20-21. há sido ainda resolvido definitivamente sobre este objeto.

Esta navegação será, incontestavelmente, a de maior importância e alcance para a provincia, já por ter de percorrer, de uma a outra de suas extremidades, a linha em que existe a maior parte de suas mais opulentas povoações, já por ser a que conduz até ao centro da Bolívia, do Peru, do Equador, da Nova Granada, e Venezuela, por meio de numerosas ramificações. ${ }^{8}$

Na proposta de João Augusto Corrêa estava contido, além do projeto para navegação do rio Amazonas, outro que previa a navegação do rio Tocantins até 0 interior de Goiás, o que também agradou a presidência do Grão-Pará. Para estabelecer esta segunda linha, requeria do governo provincial um privilégio de exclusividade de trinta anos, acrescido de um empréstimo de trinta contos de réis, que seria restituído aos cofres públicos em um prazo de dez anos. 0 presidente Fausto Augusto de Aguiar ponderou sobre os benefícios decorrentes desta atividade, e recomendou ao legislativo provincial que concedesse o empréstimo requerido, para que as obras que tornariam possivel a navegação a vapor pelo Tocantins fossem iniciadas o mais rápido possível. ${ }^{9}$ Já quanto ao privilégio pedido ele nada poderia fazer, já que era de competência do governo central concedê-lo.

Mesmo com todo o empenho do presidente paraense, entretanto, dois anos depois da apresentação do projeto o quadro acerca da navegação do Tocantins e do Araguaia ainda era sombrio. 0 presidente José Joaquim da Cunha referia que, provavelmente, esta navegação - que então já estava sendo realizada por uma companhia de Goiás - teria de ficar interrompida por muitos anos, devido às dificuldades que faziam com que as despesas de tal empresa fossem muito maiores do que suas receitas. 10 De fato era geral, em meados do século XIX, a percepção de que a falta de atrativos econômicos era o principal obstáculo para o estabelecimento de linhas regulares de vapores em várias regiões do interior do Império. Se para a navegação costeira havia sempre a possibilidade de transporte de mercadorias oriundas do comércio externo - lucrativo o suficiente para se constituir na principal fonte de rendas do governo central -, no tocante à navegação fluvial essa possibilidade, ainda que existente, oferecia muito menor potencial de lucros, já que se tratava predominantemente de transporte interprovincial e de trocas realizadas com paises com os quais o Império não possuía um histórico de relações comerciais vultosas - como Venezuela, Nova Granada, Peru e Bolívia.

Embora existisse uma propensão do governo central para mudar este quadro, isto por si só não resolvia todos os problemas enfrentados pela administração provincial. A questão era simples: embora o governo central estivesse tomando medidas mais efetivas para o desenvolvimento da região norte e para o estabelecimento de uma navegação a vapor efetiva no rio Amazonas, seus interesses não eram inteiramente coincidentes com os do governo do Grão-Pará. Ambos queriam o estabelecimento de linhas regulares de vapor no grande "rio-mar", ambos concordavam que, com isso, o comércio se desenvolveria, bem como as relações com os vizinhos, o que traria dividendos para a província e para o Império. No entanto, permanecia uma questão que, apesar de ser central para a administração paraense, era apenas tangenciada pelas medidas vindas da Corte: as comunicações com as regiões mais distantes do Grão-Pará.

Para o governo central a navegação a vapor era uma questão econômica e política, do ponto de vista de uma inserção mais efetiva da região norte no conjunto do Império e das trocas internacionais. Para o governo provincial a situação era um pouco mais complicada. Além destes obje- 
11

Relatório apresentado ao Exmo. Sr. Dr. José Joaquim da Cunha, presidente da província do Grão-Pará, pelo Comendador Fausto Augusto de Aguiar, por ocasião de entregar-Ihe a administração da província no dia 20 de agosto de 1852, p.57. tivos, era preciso garantir comunicações mais eficientes com o interior da província, tornando a administração mais eficiente e evitando a repetição dos distúrbios que haviam levado à Cabanagem. A navegação era, portanto, mais do que uma questão de viabilidade econômica, uma necessidade que garantiria sua existência política. Seria apenas através da aproximação da administração dos pontos mais distantes da província que se garantiria, em última instância, sua manutenção como parte integrante do Império brasileiro. E seria esta, também, a única forma de garantir ao governo provincial os meios necessários para se manter efetivo (tais como a capacidade de recolhimento de tributos, de monopólio do uso da força, de controle das populações, entre outros). A elevação da comarca do Alto Amazonas á categoria de província, em 1850, veio atender exatamente a esta necessidade. Mas os presidentes paraenses foram unânimes em afirmar que esta medida não esgotava o problema.

Nos debates ocorridos no Legislativo do Rio de Janeiro e nos documentos produzidos pelo governo central estes elementos, quando aparecem,

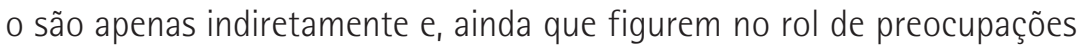
do governo central, não possuem o caráter central que os presidentes de provincia Ihe dão. Neste sentido, pode-se afirmar que o governo localizado na Corte tendia a visualizar a questão em termos mais amplos, que englobavam interesses e projetos de cunho nacional. Já a administração paraense, embora compartilhasse desses mesmos valores, não podia esquecer os problemas específicos da sua própria região. Fica claro, portanto, o porquê de, mesmo existindo uma colaboração estreita entre as duas esferas de poder, o governo provincial não abrir mão de seus próprios esforços em estabelecer a navegação a vapor em regiões e com objetivos não contemplados pelas medidas vindas do Rio de Janeiro.

É neste sentido que podem ser entendidos todos os esforços do Executivo paraense para instituir, por seus próprios meios, a navegação a vapor em vários pontos da província. Em 1852, por exemplo, mesmo com a iminência da assinatura, pelo governo central, de um contrato para a navegação do rio Amazonas, o presidente José Joaquim da Cunha referia providências para facilitar a navegação entre Belém e as vilas de Bragança e Turiassú. Esta navegação, originalmente, era realizada pela costa, em uma região considerada perigosa por conta dos ventos e ondas que ocorriam com freqüência e dimensões acima da média, além dos baixios que avançavam "até mais de 7 milhas pelo mar". Para facilitar esta comunicação era requerido do poder central que enviasse verbas para realização de obras em alguns canais naturais destinadas a torná-los navegáveis, - alargamentos, escavações no leito, limpeza das margens, cortes para diminuir as curvas, etc. - possibilitando, assim, que a comunicação com as vilas fosse feita pelo interior da província com mais rapidez e segurança:

\footnotetext{
Sendo estes trabalhos de mui grande e evidente utilidade às relações comerciais de toda a parte da província compreendida entre esta capital e as vilas de Bragança e Turiassú, e na qual se acham as da Vigia, de Cintra, e de Curuça, e a freguesia de Salinas, levei o sobredito relatório ao conhecimento do Governo Imperial, e fundado no aviso de 10 de fevereiro deste ano, pedi autorização para mandar fazer as indicadas obras pelos cofres gerais. ${ }^{11}$
}

Se as obras de fato incrementariam o comércio entre as citadas regiões não nos é dado saber, mas o fato é que, pelo menos, atingiriam o objetivo de facilitar as comunicações com algumas das várias povoações da província, facilitando sua administração. 
12

Fala que o Exmo. Sr. Dr. José Joaquim da Cunha, presidente desta província, dirigiu a Assembléia Legislativa provincial, na abertura da mesma assembléia, no dia 15 de agosto de 1853, p.19-20.
13

Ibidem, p.21.

\section{4}

Fala que o Exmo.Sr. Conselheiro Sebastião do Rego Barros, presidente desta província, dirigiu á Assembléia Legislativa provincial, na abertura da mesma assembléia no dia 15 de agosto de 1854, p.33.

\section{Esforços para complementar a ação da Companhia de Navegação e Comércio do Amazonas}

0 ano de 1853 foi decisivo para o esforço de dotar a região amazônica de uma navegação a vapor regular. No primeiro dia do mês de janeiro, após a assinatura de um contrato de prestação de serviços entre o futuro barão de Mauá e o governo central, iniciaram-se as atividades das primeiras linhas regulares no rio Amazonas, com a viagem entre Belém e a vila da Barra do Rio Negro (mais tarde Manaus), realizada pelo vapor Marajó. Apesar da pequena procura no início das atividades, o presidente da província, José Joaquim da Cunha, vaticinou um futuro glorioso para a região, apesar dos inúmeros obstáculos que a navegação a vapor ainda enfrentava - os rios Madeira, Tapajós, Tocantins e Xingú ainda não seriam navegáveis em toda a sua extensão, podendo esta dificuldade ser removida com a realização de algumas obras. Em breve os vapores da companhia chegariam a Nauta, no Peru, e o presidente previa um incremento no comércio internacional e a contratação do serviço de navegação também por parte dos governos dos países vizinhos. ${ }^{12}$

0 tom da fala presidencial era evidentemente de euforia, mas nem tudo foram flores em seu discurso. Aqui, novamente aflorou um dos elementos necessários para o bom andamento da relação entre as esferas central e provincial do poder - a necessidade de colaboração para a consecução de objetivos comuns:

\section{Um futuro brilhante se prepara ao território banhado pelo Amazonas e seus tributários, mas esse futuro ficará mui remoto se tudo se esperar do tempo e do governo central. Não basta que o governo tenha promovido a navegação e a colonização com grande sacrificio dos cofres públicos, é preciso secundá-lo nas suas vistas, que se dirigem a outros muitos melhoramentos materiais do Império, à repressão do tráfico africano, do contrabando e da moeda falsa, e finalmente à guerra tanto estrangeira quanto intestina, que tanto nos tem retardado 0 progresso e a civilização, e de que esta província já foi teatro. ${ }^{13}$}

0 recado do presidente José Joaquim da Cunha era claro: sem a colaboração estreita entre as duas esferas de poder nada se faria, ou se faria apenas com muito custo e demora. Este discurso possui grande significado por ser dirigido à Assembléia Legislativa paraense, órgão responsável não apenas pela elaboração de leis a nível regional, mas também pela liberação de verbas orçamentárias para a realização de obras e outros melhoramentos. Representa o reconhecimento de que a administração provincial também deveria colaborar para o bem da navegação a vapor que, afinal de contas, seria a garantidora de seu progresso futuro. Ocupado com questões e interesses de cunho nacional, não seria dado ao governo central conhecer todas as demandas especificas da população que ocupava um território representativo de um quarto do total do Império. Apenas quem vivia na província teria condições de conhecer e buscar atender a todas as suas necessidades. Daí a imensa importância desta esfera de poder secundar os esforços da Corte para o estabelecimento das linhas de navegação a vapor do Amazonas.

As providências do governo provincial para maximizar as vantagens desta empresa não demoraram a surgir. Em 15 de novembro de 1853 a lei provincial n²26 criou no tesouro público provincial um caixa especial destinado exclusivamente a adiantar fundos às empresas que fossem formadas com o objetivo de introduzir colonos na província. ${ }^{14}$ É interessante perceber que em sua fala o presidente Sebastião do Rego Barros 
Um exemplo de como esta negociação se dava na Corte pode ser observado nos debates ocorridos no Parlamento acerca do contrato assinado entre o governo central e Irineu Evangelista de Souza, em 1852. Depois de muitas críticas ao que os deputados e senadores entenderam ser uma "invasão da jurisdição exclusiva do Poder Legislativo", por parte do Executivo, o privilégio de exclusividade de trinta anos, concedido sem qualquer consulta aos parlamentares, foi reprovado pela maioria. 0 resultado disto foi a assinatura de um novo contrato em 1854, no qual o privilégio não estava mais presente, substituído por algumas das principais reivindicações dos membros do Legislativo, em um evidente recuo do Poder Executivo. Mais detalhes sobre estes debates podem ser encontrados em: GREGÓRIO, Vitor Marcos. Uma face de Jano: a navegação do rio Amazonas e a formação do Estado brasileiro (1838-1867), Dissertação de mestrado, FFLCH USP, 2008, Capítulo 2.

\section{6}

Nestes documentos o termo "indústria" possui significado diverso do que o atribuimos hoje. No século XIX entendia-se por "indústria" toda e qualquer atividade de cunho econômico. Assim, falava-se da "indústria da extração", "indústria da pesca", entre outras.

\section{7}

Segundo Synesio Sampaio Goes Filho, o governo imperial chegou a mostrar-se contrário, em várias oportunidades, à adoção deste princípio como parâmetro para regular as discussões de fronteira, por considerá-lo lesivo aos interesses nacionais. Foi apenas em 1849, quando Paulino José Soares de Souza (depois visconde do Uruguai) assumiu o ministério dos Negócios Estrangeiros, que o uti possidetis teria se tornado o pilar principal das discussões acerca dos limites do Império, influenciando poderosamente nas políticas destinadas a manter a posse brasileira sobre a região amazônica - GÓES FILHO, Synesio Sampaio. Navegantes, bandeirantes, diplomatas - um ensaio sobre a formação das fronteiras do Brasil. Rio de Janeiro: Martins Fontes/Biblioteca do Exército, 2000. p.206-208.

\section{8}

Fala que o Exmo.Sr. Conselheiro Sebastião do Rego Barros, presidente desta província, dirigiu á Assembléia Legislativa provincial, na abertura da mesma assembléia no dia 15 de agosto de 1854, p.40.

\section{9}

Em 1854, por exemplo, baseado nas leis provinciais $n^{\circ} 226$, de 15 de dezembro de 1853, e $n^{\circ} 263$, de 13 de outubro de 1854, o presidente Sebastião do Rego Barros assinou contratos com João Augusto Corrêa e João Pinto de Araújo para a introdução, respectivamente, de 250 colonos europeus em um ano e 800 colonos europeus em dois anos, mediante subvenção e outras vantagens; no mesmo ano, o novo contrato firmado entre Irineu Evangelista de Souza e o governo imperial previa o resgate do privilégio de exclusividade, ao mesmo tempo em que aumentava os valores das subvenções pagas e obrigava a companhia a fundar colônias nas margens do rio Amazonas - Exposição apresentada pelo Exmo. Sr. Conselheiro Sebastião do mostrou-se francamente contrário à edição desta lei, aceitando-a como um fato consumado ditado apenas pelas "boas razões" da Assembléia Provincial. Um exemplo de que na província, assim como na Corte, a relação entre os poderes Executivo e Legislativo não era baseada unicamente na subserviência sistemática de um às deliberações do outro, mas sim em uma negociação constante segundo a qual, dependendo das circunstâncias e dos interesses em jogo, um ou outro dos poderes poderia lograr ver seus projetos postos em prática. ${ }^{15}$

A falta de mão de obra sempre foi apontada nos documentos provinciais como uma das principais causas da decadência da agricultura, da ausência de indústrias ${ }^{16}$ e, conseqüentemente, da estagnação econômica da região. Sem este elemento seriam desperdiçados todos os abundantes recursos naturais da região, não se alcançaria o objetivo de povoar e desenvolver a província e, ainda mais grave, tornar-se-ia dificultosa a posição brasileira quando fosse necessário discutir a questão das fronteiras com seus vizinhos, uma vez que ganhava cada vez mais espaço na diplomacia imperial o princípio do uti possidetis - segundo o qual um território em litígio deveria pertencer a quem de fato o ocupava - para regular estes debates. ${ }^{17} 0$ problema ficava ainda mais grave com o aumento da extração da borracha e com sua valorização no mercado internacional, o que faria com que cada vez mais pessoas abandonassem a agricultura para embrenhar-se nas matas em atividades sazonais destinadas à obtenção da preciosa goma elástica:

Isto é certamente um mal; tanto mais porque os lucros avultadissimos dessa indústria, que absorve e aniquila todas as outras, longe de tenderem à criação da pequena propriedade com sua permanência e suas vantagens, e à divisão da riqueza, só dão em último resultado acumularem esta em poucas mãos, e pela maior parte estrangeiras, acarretando a miséria à grande massa daqueles após que ela abandonam seus lares, seus pequenos estabelecimentos, e talvez suas famílias, para se entregarem a uma vida de incerteza, privações, e na qual os ganhos da véspera evaporam-se no dia seguinte. ${ }^{18}$

As políticas de importação de mão de obra passaram a ser apresentadas como uma das mais necessárias para a província, e pedidos de auxílio do governo central na adoção destas políticas, bem como a elaboração de medidas provinciais como a lei $n^{\circ} 226$ passaram a ser uma constante a partir da década de $1850 .^{19}$ E as medidas para a introdução de linhas de vapores nos trechos não contemplados pela companhia de navegação do Amazonas também não seriam abandonadas. Neste sentido, em 20 de dezembro de 1853, a resolução provincial n 230 autorizava o governo a contratar com qualquer companhia a navegação a vapor entre a ilha de Marajó e Belém. 0 objetivo desta atividade seria abastecer de gado a capital e transportar passageiros e mercadorias entre os dois portos, passando também pelos de Cametá e vila da Vigia, num total de três linhas. Para atrair interessados, a resolução previa o pagamento de uma subvenção, pelos cofres provinciais, de trinta contos de réis pelo prazo de três anos. Também pelo tesouro público provincial seriam executadas as multas impostas pelo governo caso a companhia contratada faltasse aos seus deveres. ${ }^{20}$ A empresa que se propusesse a realizar o serviço deveria ter um capital mínimo de quinhentos contos de réis e possuir três vapores, os quais entrariam em serviço, respectivamente, após seis, oito e dez meses da assinatura do contrato. Outra obrigatoriedade com relação aos barcos 
Rego Barros, presidente da província do GrãoPará, por ocasião de passar a administração da mesma província ao $1^{\circ}$ Vice-Presidente, o Exmo. Sr. Dr. Ângelo Custódio Corrêa, 1855. p.8

\section{0}

Colecção das Leis da Província do Grão-Pará, Tomo XV, Parte 1a, Resolução n² 230, de 20 de dezembro de 1853, p.17-18.

21

Fala com que o Exmo. Sr. Conselheiro Sebastião do Rego Barros, presidente desta província, dirigiu a Assembléia Legislativa provincial, na abertura da mesma assembléia, no dia 15 de agosto de 1854, anexo E, p.1-6.

\section{2}

Relatório apresentado á Assembléia Legislativa Provincial do Pará, no dia 15 de agosto de 1856 por ocasião da abertura da primeira sessão da 10. Legislatura da mesma Assembléia, pelo presidente Henrique de Beaurepaire Rohan, p.14.

23

Ibidem, p.23.
24

Relatório apresentado á Assembléia Legislativa Provincial do Pará, no dia 15 de agosto de 1857, por ocasião da abertura da segunda sessão da 10. Legislatura da mesma Assembléia, pelo presidente Henrique de Beaurepaire Rohan, p.25. designava que estes deveriam ser nacionalizados, independentemente do local de sua construção. ${ }^{21}$

0 abastecimento da capital de gêneros essenciais (alimentos e matérias-primas, principalmente) aparece com freqüência na documentação provincial como uma das principais preocupações do governo. As mesmas dificuldades que obstavam as comunicações eficazes com o interior da província faziam com que estas mercadorias estivessem constantemente em falta no mercado de Belém, sendo esta uma questão que a administração provincial tentou por várias vezes contornar da melhor forma possivel. Já no século XIX a ilha de Marajó possuía grandes centros criadores de gado bovino, e nada seria mais natural, portanto, que o estabelecimento de uma linha regular de vapores que propiciasse o intercâmbio comercial entre esta região e a capital paraense. Ao mesmo tempo, a medida adotada deixava mais uma vez clara a preocupação do governo provincial em facilitar as comunicações com o interior, ao obrigar a companhia a estabelecer linhas regulares, também, entre a capital e as localidades de Cametá e da vila da Vigia.

A navegação a vapor prosperava na província ao longo da década de 1850. Em todos os relatórios elaborados pelos presidentes nesta época, entre medidas e preocupações relacionadas a politicas de colonização, como a discussão sobre qual tipo de colono seria mais favorável à região amazônica22 - os relatos de sucessos no comércio e nos transportes intraprovinciais tornaram-se comuns. No entanto, o governo provincial não abdicou de medidas tendentes a atender seus próprios interesses neste contexto. Assim, em 1856 o presidente Henrique de Beaurepaire Rohan defendeu perante a Assembléia Legislativa a construção de uma estrada capaz de transportar para a província o gado originário do interior do Maranhão, mediante acerto com aquela administração. As obras começaram, de fato, em 1857. Ao mesmo tempo, referia a continuação das obras para a abertura de outra estrada, ligando Belém a Bragança, o que ofereceria mais um meio de comunicação entre as duas cidades. ${ }^{23} \mathrm{Um}$ ano depois seu recado seria mais claro: embora reconhecesse que o sistema de navegação a vapor da província havia melhorado consideravelmente desde o início das atividades da companhia de Irineu Evangelista de Souza, demonstrava expressamente que o governo provincial não estava plenamente satisfeito com os serviços prestados:

\footnotetext{
Não obstante as grandes vantagens que se tem colhido, depois do estabelecimento dos barcos de vapor nesta província, cumpre todavia reconhecer-se que ela não tem ainda tomado suficiente desenvolvimento. Pontos há a que não chegam os vapores, como sejam, na primeira linha, Porto de Moz, e Monte Alegre. A cidade de Macapá, e a vila de Chavez, á entrada do Amazonas, estão privadas dos benefícios dessa navegação; e o mesmo acontece ás cidades de Bragança, Vigia, vila de Cintra, Monsarás, etc.

Não só ao comércio, como á administração pública, conviria que houvesse vapores, que tocassem regularmente nesses portos. ${ }^{24}$
}

Expresso o descontentamento, caberia ao governo provincial suprir as lacunas apontadas. Daí o desabafo ter sido feito, não por acaso, em um relatório encaminhado à Assembléia Legislativa. Ao entregar o cargo, o presidente Rohan recomendou a seu sucessor, como uma medida indispensável, a realização de obras no canal de Igarapé-Mirim para torná-lo navegável por barcos a vapor, com o objetivo de tornar as vilas de Igarapé-Mirim 
25

Relatório apresentado ao IImo. e Exmo. Sr. Dr. João da Silva Carrão, no ato de ser empossado na presidência da província do Pará, por Henrique de Beaurepaire Rohan, 1857. p.9-10.

\section{6}

Relatório lido pelo Exmo. Sr. Vice-Presidente da Província, Dr. Ambrósio Leitão da Cunha, na abertura da primeira sessão ordinária da $11^{\text {a }}$ Legislatura da Assembléia Legislativa Provincial, no dia 15 de agosto de 1858 (título do documento parcialmente ilegivel). p.35-42.

27

Fala dirigida á Assembléia Legislativa da província do Pará, na segunda sessão da XI Legislatura, pelo Exmo. Sr. Tenente-Coronel Manoel de Frias e Vasconcellos, presidente da mesma província, em 1 de outubro de 1859, p.55. Em 1857 foi realizada nova reforma do contrato assinado entre o governo central e Irineu Evangelista de Souza. Esta foi motivada pelas afirmações do empresário de que não seria possivel continuar as atividades de sua companhia com os encargos contraídos pelo contrato de 1854 . Neste documento, além de perder o privilégio de exclusividade originalmente concedido em 1852, ele ficou obrigado a fundar várias colônias ao longo das margens do rio Amazonas e novas linhas de vapores ligando vários pontos anteriormente não contemplados pelo acordo. Pelo novo contrato que entraria em vigor a partir de 1858 , o futuro barão de Mauá ficou desobrigado da fundação das colônias, e obteve um aumento da subvenção pecuniária oferecida pelo governo para a fundação das novas linhas de vapores. GREGÓRIO, Vitor Marcos. Uma face de Jano: a navegação do rio Amazonas e a formação do Estado brasileiro (1838-1867), Dissertação de mestrado, FFLCH - USP, 2008.

28

GREGÓRIO, Vitor Marcos. Op.Cit., p.61-62.
Uma obra de muita importância, em relação á navegação a vapor entre esta cidade e a de Cametá, é o canal de Igarapé-mirim, que comunica o rio Mojú com o Muritípucú. Este canal já é antigo, e por ele navegam canoas; mas não está disposto para o trânsito de barcos a vapor, sobre tudo por causa de certas sinuosidades, que são aliás fáceis de destruir. Convenientemente preparado, seria da maior vantagem, porque tornaria as vilas de Mojú e Igarapé-Mirim pontos de escalas de muito interesse, não só para a companhia de navegação e comércio do Amazonas, como para os habitantes daqueles lugares. 25

O sentimento de que a navegação provincial poderia melhorar, mesmo com o progresso representado pela companhia fundada pelo futuro barão de Mauá, continuou em 1858. Em seu relatório enviado à Assembléia Legislativa o presidente Ambrósio Leitão da Cunha repetiu este argumento, com um agravante: o contrato assinado pela companhia com o governo peruano havia expirado. Após tecer considerações sobre as crescentes vantagens para a província oriundas deste comércio, o presidente pediu o auxilio do governo central para que um novo contrato fosse elaborado e posto em prática o mais rápido possível. Entre estas vantagens estava listada a grande possibilidade de desenvolvimento econômico decorrente da contingência de os peruanos passarem a realizar seu principal comércio internacional através do vale do Amazonas, evitando assim a cordilheira dos Andes. ${ }^{26}$ Desta forma, o grande rio tornar-se-ia um corredor de escoamento perfeito não apenas para o Peru, mas para todos os demais países da região. Com isso lucrariam os governos central e provincial, graças ao aumento da receita alfandegária decorrente da reexportação dos produtos destas regiões. Ganhariam também com o conseqüente aumento do comércio realizado por esta via, o que criaria lucros, ainda, para todos os envolvidos na empresa. Desta forma, a renovação do acordo com o governo peruano tornava-se vital para o futuro do Grão-Pará, não podendo, portanto, escapar às considerações do seu presidente.

A renovação do contrato do governo central com o futuro barão de Mauá, que desobrigava sua companhia de fundar colônias nas margens do Amazonas, também foi referida pelo governo paraense. Aqui, ela foi apontada como uma medida negativa para a continuidade das políticas de colonização da província. ${ }^{27}$ Para piorar o quadro, o ano de 1859 apresentou uma diminuição das quantidades de gêneros transportados pelos vapores da primeira linha da companhia, o que significava um abalo no comércio provincial, creditado às cheias anormais do rio Amazonas. ${ }^{28}$ Nestes termos, todo acréscimo que pudesse ser feito às comunicações e, conseqüentemente, ao comércio da província seria ainda mais bem-vindo, e o governo provincial não desistiu de tentar realizá-lo por seus próprios meios, ainda que auxiliado por outras administrações:

Por decreto n 2197 de 26 de Junho de 1858 S. M. 0 Imperador houve por bem aprovar o contrato celebrado pelo Ministério do Império com a companhia de navegação a vapor do Maranhão, para a navegação costeira entre os portos de S. Luís do Maranhão e as capitais do Ceará e Pará.

Por esse contrato, de que já existe cópia na Secretaria desta Assembléia, sabeis que á companhia cumpre tocar nos portos de Bragança e da Vigia, ambos nesta província.

Avaliais perfeitamente quão vantajosa é para a província do Pará a navegação a 
29

GREGÓRIO, Vitor Marcos. Uma face de Jano: a navegação do rio Amazonas e a formação do Estado brasileiro (1838-1867), Dissertação de mestrado, FFLCH - USP, 2008. p.62.

30

As linhas citadas são: Belém - Macapá, com escalas na ilha deMarajó, e Santarém - Povoações do Tapajós, Monte Alegre e Alemquer. Relatório apresentado ao Exmo. Sr. Ângelo Thomaz do Amaral, pelo primeiro VicePresidente da província do Grão-Pará, o Exmo. Sr. Dr. Fábio Alexandrino de Carvalho Reis, 8 de agosto de 1860, p.6.

31

Colecção das Leis da Província do Grão-Pará, Tomo XXII, Parte 1a, Lei no 359, de 6 de outubro de 1860, p.11-13. vapor entre a sua capital, e as povoações da costa; atualmente faz-se essas comunicações por meio de barcos e canoas com imensa demora e perigo. Se aos portos de escala determinados no contrato se adicionasse os de Cintra e Viseo muito lucraria a província e sua administração.

(...)

Empresas destas em nosso país não se podem sustentar por ora sem subvenção dos cofres públicos, o governo geral o reconheceu quanto á esta mesma companhia, e ás províncias do Maranhão e Ceará consta-me que seguiram já esse exemplo, que vós por certo imitareis, auxiliando uma empresa que tantas vantagens promete ás três províncias. ${ }^{29}$

A década de 1860 começou com medidas mais radicais. Após receber de seu antecessor um relatório chamando a atenção para a necessidade de introduzir a navegação em outros rios da provincia além do Amazonas, e de instituir linhas regulares apresentadas como estratégicas para a região ${ }^{30}, 0$ presidente Ângelo Thomaz do Amaral sancionou a lei provincial n 359, de 6 de outubro de 1860, com o objetivo de atender a estas e outras reivindicações. Segundo a lei, o governo ficava autorizado a subvencionar com até vinte e quatro contos de réis anuais, pelo prazo de dez anos, qualquer empresário ou companhia que se propusesse a realizar a navegação a vapor em rios do interior da província, principalmente entre os portos de Belém e os de Muaná, Soure, Chaves e Macapá. ${ }^{31}$

Os resultados não tardaram a aparecer. Em seu relatório dirigido ao vice-presidente em 4 de maio de 1861, Ângelo Thomaz do Amaral anexou uma proposta de contrato apresentada por Antônio José de Miranda, Joaquim José de Assis e Antônio Ricardo de Carvalho Penna. Segundo o documento, os empresários comprometiam-se a organizar uma companhia com o objetivo de realizar a navegação a vapor entre Belém e a ilha de Marajó, com escalas nos portos das vilas de Soure, Muaná, Chaves e da cidade de Macapá. Caso não conseguissem arrecadar fundos suficientes para a fundação da companhia, comprometiam-se a realizar a empresa com recursos próprios.

0 serviço deveria iniciar-se um ano após a assinatura do contrato e do aval do governo central para os privilégios que dependessem dele, sob pena de tornar-se nulo o acordo. Esta cláusula por si só já demonstra a urgência do governo provincial em estabelecer as linhas que estavam sendo contratadas, e a necessidade de concordância da Corte do Rio de Janeiro no tocante aos favores que fugiam da jurisdição provincial. Importante ressaltar, entretanto, que essa necessidade de aprovação não impedia a administração paraense de buscar atender às suas necessidades utilizandose de seus próprios meios. Mais do que uma relação de completa dependência com relação a administração central, o que se delineia aqui é uma situação de complementaridade, na medida em que a chancela imperial só foi requisitada para os elementos constitucionalmente definidos como sendo de sua alçada.

Pelo espaço de três anos, os empresários obrigavam-se a realizar ao menos uma viagem mensal entre os portos contratados, e após este período seria negociada com o governo provincial uma nova regularidade. Em troca dos serviços prestados, seria oferecida aos empresários uma subvenção de quatro contos e quinhentos mil réis por viagem realizada, pelo prazo de vinte anos e a ser paga pelos cofres provinciais. Além disso, seria realizada a doação, dependente de aprovação do governo central, de terrenos devolutos nos portos de escala da nova linha, para realização das obras necessárias à 
32

Relatório do Exmo. Sr. Ângelo Thomaz do Amaral, presidente da província do Grão-Pará ao Exmo. Vice-Presidente Olyntho José Meira, por ocasião de passar-lhe a administração da mesma, 4 de maio de 1861, anexo n 15, p.I-III.

33

Vários destes debates estão presentes em: GREGÓRIO, Vitor Marcos. Uma face de Jano: a navegação do rio Amazonas e a formação do Estado brasileiro (1838-1867), Dissertação de mestrado, FFLCH - USP, 2008.

34

Colecção das Leis da Província do Grão-Pará, Tomo XXIII, Parte 1a, Lei $n^{\circ} 382$, de 5 de outubro de 1861, p.7-9.

\section{5}

Relatório dirigido á Assembléia Legislativa da província do Pará, na segunda sessão da XII Legislatura, pelo Exmo. Sr. Dr. Francisco Carlos de Araújo Brusque, presidente da mesma província, em 17 de agosto de 1861, p.14

\section{6}

É possivel supor que se trate do mesmo Antônio José de Miranda que intentou realizar o contrato de navegação com o governo provincial; não foram encontrados, entretanto, indícios fortes o suficiente que permitam concluir pela acidental inversão de nomes nos documentos. Relatório apresentado á Assembléia Legislativa da província do Pará, na primeira sessão da XIII Legislatura, pelo Exmo. Sr. presidente da província, Dr. Francisco Carlos de Araújo Brusque, em $1^{\circ}$ de setembro de 1862, p.71. sua manutenção. Foram prometidas também isenções, ainda dependentes de aval da Corte do Rio de Janeiro, de direitos que deveriam ser pagos na aquisição, cadastramento e nacionalização dos vapores comprados pela companhia, além de outras "vantagens que têm sido concedidas e estipuladas para empresas semelhantes" - como a dispensa do recrutamento militar dos empregados nacionais contratados para a realização do serviço. Aos empresários seria, ainda, completamente livre a cessão ou repasse do contrato assinado, sem qualquer restrição. ${ }^{32}$

Esta proposta é bastante esclarecedora dos interesses do governo paraense no tocante à navegação de seus rios. Determinando como prazo máximo para o início das atividades o periodo de um ano, ficava demonstrada toda a urgência no estabelecimento desta empresa. Como era normal neste tipo de documento, cláusulas prevendo a requisição dos vapores a bem do serviço público também estavam presentes, garantindo a possibilidade de seu uso pela administração provincial em casos mais graves. Mas o que chama a atenção são os cuidados tomados para a garantia de prestação do serviço mesmo que algo desse errado com os empresários. Se não conseguissem reunir os fundos necessários para formação de uma companhia, poderiam estabelecer a linha de vapores com recursos próprios. Se mesmo assim ficassem impossibilitados de honrar seus compromissos, tinham garantido o direito de repassar o contrato a terceiros sem qualquer restrição, ou seja, podendo até mesmo vendê-lo para quem desejassem. Em anos anteriores, ásperos debates ocorridos no Parlamento acabaram por condenar a possibilidade de repasse dos contratos assinados pelo governo imperial para realização de empresas estratégicas para o país. ${ }^{33}$ Tendo isto em mente, é possível vislumbrar a novidade representada por esta permissão, e o grau de autonomia experimentado pelo governo provincial na tomada de decisões referentes a seus interesses mais urgentes.

Com o objetivo de atrair mais interessados, o governo provincial elaborou a lei no 382, de 5 de outubro de 1861. Formado por quatro artigos, este documento tinha como único objetivo alterar o primeiro artigo da lei $n^{\circ} 359$, de um ano antes. Ao invés de oferecer à companhia contratada uma subvenção de vinte e quatro contos de réis, agora o auxilio oferecido passava a ser no valor de sessenta contos de réis. Como compensação, houve um aumento do itinerário que deveria ser seguido pelos vapores. Além da linha original entre o porto de Belém e os de Soure, Muaná, Chaves e Macapá, ficava definido que os barcos deveriam chegar, também, a algum porto do rio Arary, a ser definido quando da assinatura do contrato. ${ }^{34}$

Antes mesmo da assinatura do acordo entre o governo paraense e os empresários Antônio José de Miranda, Joaquim José de Assis e Antônio Ricardo de Carvalho Penna, é importante perceber que a partir de 1861 os relatórios da presidência da província passaram a citar com freqüência a existência de um vapor particular, além dos já tradicionais barcos da Companhia de Navegação e Comércio do Amazonas, realizando uma navegação regular no interior da província. ${ }^{35}$ No relatório de 1862 aparece citado o nome do proprietário do vapor em questão, José Antônio de Miranda, muito provavelmente da família de João Antônio de Miranda, ex-presidente da província do Grão-Pará. ${ }^{36}$ As questões de importância para a província poderiam até estar sendo resolvidas, mas os interesses pessoais e familiares não podiam, evidentemente, ser completamente esquecidos. 
37

Relatório apresentado á Assembléia Legislativa da província do Pará, na primeira sessão da XIII Legislatura, pelo Exmo. Sr. presidente da província, Dr. Francisco Carlos de Araújo Brusque, em $1^{\circ}$ de setembro de 1862, p.73

38

Relatório apresentado á Assembléia Legislativa da província do Pará, na segunda sessão da XIII Legislatura, pelo Excelentíssimo Senhor Presidente da Província Doutor Francisco Carlos de Araújo Brusque, em $1^{\circ}$ de novembro de 1863, p.65.

\section{9}

Colecção das Leis da Província do Grão-Pará, Tomo XXV, Parte 1a, Lei no 448, de 3 de outubro de 1864 , p.18-19

\section{0}

Relatório dos negócios da província do Pará, seguido de uma viagem ao Tocantins até a cachoeira das Guaribas e ás bahias do rio Anapú, pelo secretário da província Domingos Soares Ferreira Penna, e da exploração e exame do mesmo rio até acima das últimas cachoeiras depois de sua juncção com o Araguaya pelo capitão-tenente da Armada Francisco Parahybuna dos Reis, 1864, p.65.
Ainda no ano de 1862 foi finalmente contratada a navegação de que tratava as leis 359 e 382 . Apesar de a primeira proposta de contrato ter sido apresentada pelos três empresários acima citados, acabou esta sendo preterida em favor da Companhia de Navegação e Comércio do Amazonas, de Irineu Evangelista de Souza. Em seu relatório publicado em $1^{\circ}$ de setembro, o presidente Francisco Carlos de Araújo Brusque procedeu a uma comparação item a item das duas propostas, buscando demonstrar as razões pelas quais escolheu a companhia que já realizava a navegação no rio Amazonas. Esta companhia, em resumo, poderia introduzir as novas linhas imediatamente e sem nenhum ônus adicional para a provincia, além da subvenção originalmente oferecida. Além disso, oferecia-se para ampliar o número de portos visitados pelos vapores, aceitava o estabelecimento de um contrato de menor duração (quinze anos contra vinte da primeira proposta) e oferecia as garantias de uma companhia já constituída e já em atividade com a prestação de serviços vantajosos à província, ao passo que, com relação à primeira proposta, eram necessários os cuidados acima analisados.

Ao final das negociações, a companhia estabeleceu três novas linhas de vapores, inteiramente subvencionadas pelos cofres provinciais. Estas partiriam de Belém em direção às vilas de Soure, Arary e Chaves, tocando ainda nos portos de Curralinho - caso para aí fosse transferida a vila de Oeiras - e da barra do Anajás, além dos demais citados nas leis. Já nas últimas negociações foram incluidos também no rol de portos contemplados pelo novo contrato os de Abaeté e Breves, ambos lembrados pela direção da companhia. 0 contrato teria duração de dez anos (menor, portanto, que a proposta inicial apresentada por Irineu Evangelista de Souza), e começou a ser efetivado praticamente de imediato. No dia 3 de maio de 1862 o vapor Tabatinga partiu de Belém rumo a vila de Soure, no dia 6 de maio para os portos do rio Arary, e no dia 15 de maio para a vila de Chaves. ${ }^{37}$

0 governo da província do Grão-Pará conseguia, finalmente, estabelecer as linhas de navegação que preenchiam algumas das lacunas deixadas pelo serviço contratado pelo governo central, e para isso utilizou-se de seus próprios recursos. As novas linhas seriam operadas com pontualidade pela Companhia de Navegação e Comércio do Amazonas $^{38}$, o que convenceu a administração provincial a contratar outras mediante aprovação da lei n० 448 , de 3 de outubro de 1864.39 Por conta de acordos assinados entre os governos brasileiro e peruano, a partir do segundo trimestre de 1863 o Amazonas passaria a ser navegado, também, por dois vapores daquele pais. 40 Era já o prenúncio da abertura a todas as nações amigas realizada pelo decreto imperial no 3749, de 7 de dezembro de 1866. Decerto esta última medida não esgotou todas as demandas do governo provincial. Não obstante, ele conseguiu demonstrar, ao longo de quase duas décadas, que embora não fosse completamente auto-suficiente com relação ao governo central, ao menos possuía autonomia bastante para buscar atender a seus próprios interesses e necessidades da forma que Ihe era possivel em diferentes circunstâncias. Certamente continuaria fazendo o mesmo após 1867.

\section{Estratégias para navegar os rios Araguaia e Tocantins}

Os interesses e necessidades do governo paraense iam além do estabelecimento de uma navegação regular nas águas do Amazonas. Alcançado este objetivo em 1853, graças a assinatura de um contrato entre o governo central e Irineu Evangelista de Souza, e aprimorado este serviço como 
Ofício, de José Vieira Couto de Magalhães, presidente da província de Goiás, a Francisco Carlos de Araújo Brusque, presidente da província do Pará, 8 de maio de 1863. In: Relatório apresentado á Assembléa Geral Legislativa na segunda sessão da décima segunda legislatura, pelo ministro e secretário de Estado dos Negócios da Agricultura, Comércio e Obras Publicas, Domiciano Leite Ribeiro, 1864, anexo, p.4.

\section{2}

Ofício, de José Vieira Couto de Magalhães, presidente da provincia de Goiás, a Joaquim Raymundo de Lamare, ministro da Marinha, 16 de maio de 1863. In: Relatório apresentado á Assembléa Geral Legislativa na segunda sessão da décima segunda legislatura, pelo ministro e secretário de Estado dos Negócios da Agricultura, Comércio e Obras Publicas, Domiciano Leite Ribeiro, 1864, anexo, p.9-10. resposta aos esforços provinciais realizados durante as décadas de 1850 e 1860, restavam ainda outros rios caudalosos a navegar. 0 estabelecimento de novas linhas em cursos d'água ainda não explorados poderia levar, imaginavam os governantes locais, ao aumento do comércio no Grão-Pará e, como conseqüência, à multiplicação da arrecadação não só deste governo como das administrações vizinhas.

Neste sentido, os rios Araguaia e Tocantins se encaixavam bem na categoria de potenciais impulsionadores da economia amazônica, mediante o estabelecimento de linhas de vapores em suas águas. Devido aos seus cursos, poderiam facilitar o escoamento das produções não apenas do interior paraense, mas também de outras províncias do Império, servindo ainda como via de comunicação privilegiada entre estas regiões e os mercados dos paises vizinhos.

Enquanto foi presidente da província de Goiás, José Vieira Couto de Magalhães percebeu o quanto poderia ser benéfico para a população sob sua administração a adoção desta medida. Neste sentido, em ofício enviado ao governo paraense em 1863, demonstrou os cálculos que apontavam as vantagens econômicas que adviriam do estabelecimento de uma navegação a vapor regular nos rios Araguaia e Tocantins, permitindo assim que o comércio daquela região pudesse ser realizado através do porto de Belém:

\footnotetext{
No primeiro dos casos o preço da arroba posta nesta capital é de $8 \$ 000$, e pelo Rio de Janeiro é de $12 \$ 000$. Se ajuntarmos a esta consideração a de que os gêneros no Pará são, segundo informações que tenho, 20\% mais baratos do que na capital do império, teremos que as mercadorias importadas do Pará chegarão a esta província com uma redução de $30 \%$ em confrontação com as que vem do Rio de Janeiro. Á vista disto me parece fora de dúvida que a navegação do Pará é de grande interesse para os habitantes de Goiás. ${ }^{41}$
}

Presídios militares já haviam sido fundados nas margens dos dois rios com o objetivo de facilitar as comunicações entre as duas províncias através da criação de portos intermediários que permitissem o reabastecimento dos navios e a defesa contra os índios. Estas medidas, entretanto, não eram suficientes. Faltava o essencial, que Couto de Magalhães solicitou ao ministério da Marinha alegando falta de meios pecuniários de sua província:

\footnotetext{
Por agora o fim deste ofício é pedir a V. Ex. que me conceda um pequeno vapor de calado de três a quatro palmos d'água, munido de competente tripulação, que, segundo as informações que temos, não poderá ser superior a 8 pessoas. Seria muito conveniente que o transporte desse pequeno vapor fosse feito a expensas do governo; se, porém não for possivel, basta que V. Ex. o mande colocar na cidade de Belém, província do Pará; bem que com muitos sacrifícios eu conseguirei meios de o trazer ao Araguaia. 42
}

0 quadro, sem dúvida, é desolador. De acordo com este ofício enviado pelo presidente ao governo central, a província sob sua administração, outrora rica fornecedora de metais preciosos para a metrópole lusitana, na segunda metade do século XIX não possuía recursos suficientes para adquirir um pequeno vapor de oito tripulantes. Aliás, teria de fazer "muitos sacrifícios" para, mesmo concedida esta embarcação, transportá-la do porto de Belém para as águas do rio Araguaia. No caso de resposta negativa, o projeto teria de ser abortado e os goianos veriam perdida uma grande oportunidade de desenvolver sua economia. 
43

Ofício, de José Vieira Couto de Magalhães, presidente da província de Goiás, a Francisco Carlos de Araújo Brusque, presidente da provincia do Pará, 8 de maio de 1863. In: Relatório apresentado á Assembléa Geral Legislativa na segunda sessão da décima segunda legislatura, pelo ministro e secretário de Estado dos Negócios da Agricultura, Comércio e Obras Publicas, Domiciano Leite Ribeiro, 1864, anexo, p.5-6.

\section{4}

Ofício, de José Vieira Couto de Magalhães, presidente da província de Goiás, a Joaquim Raymundo de Lamare, ministro da Marinha, 16 de maio de 1863. In: Relatório apresentado á Assembléa Geral Legislativa na segunda sessão da décima segunda legislatura, pelo ministro e secretário de Estado dos Negócios da Agricultura, Comércio e Obras Publicas, Domiciano Leite Ribeiro, 1864, anexo, p.9.
Não era essa, entretanto, a situação apresentada por Magalhães ao seu colega, Francisco Carlos de Araújo Brusque. Buscando convencer presidente do Grão-Pará das vantagens da empresa pretendida, o administrador de Goiás antecipava, em correspondência, o pedido enviado à Corte do Rio de Janeiro, apresentando-o, entretanto, em colorações bastante diferenciadas:

\begin{abstract}
Mandei pedir ao governo imperial, e conto ser atendido, um pequeno vapor de calado de 15 a 18 polegadas para ser posto no Araguaia, fazendo o transporte dos gêneros de Santa Maria para Leopoldina, onde o rio não oferece o mais pequeno embaraço. Se o governo imperial em sua sabedoria julgar que não deve atender-me estou me munindo com os fundos necessários para comprá-lo á custa da província [grifo meu]. Nesta última hipótese desejo desde já estar habilitado com as informações precisas e por essa razão as peço a V. Ex., rogando que se digne informar-me sobre os seguintes pontos: $1^{\circ}$ - Se é possivel comprar-se ai no Pará, um pequeno vapor nestas condições, porque preço e a quem. $2^{\circ}$ - Se não sendo possivel comprar-se aí no Pará, encontrar-se-á aí negociante que se queira encarregar de mandá-lo vir da Europa, ou dos Estados Unidos por quanto e em que condição. $3^{\circ}$ - Qual a diferença que farão nos preços, na hipótese de ser o pagamento á vista [grifo meu], ou em três prestações, sendo a primeira á vista, e as duas outras com intervalo cada uma de um ano. $4^{\circ}$ - Qual a diferença no preço entre um vapor de ferro, e um de madeira; qual o tamanho mínimo dos vapores, vindo explicado o comprimento, a largura, a tonelagem e calado, o peso e altura das peças mais elevadas, e se será possivel encontrar aí um maquinista, e a necessária tripulação; porque preço se poderá obter cada uma dessas coisas. $5^{\circ}$ - Em que tempo poderá vir a encomenda da Europa ou dos Estados Unidos. $6^{\circ}$ - Por quanto se poderá obter um vapor nas mesmas condições, de ferro, porém vindo desmanchado; neste caso, em quantas peças poderá vir; qual o peso e o volume e o peso aproximado de cada uma. $7^{\circ}$ - Qual o preço provável de um maquinista armador; quais os utensílios e meios indispensáveis para pôr-se o vapor a nado, e qual o preço. ${ }^{43}$
\end{abstract}

Longe de relatar a penúria de recursos apresentada ao governo central, para seu colega paraense o presidente goiano não apenas demonstrava a necessidade da aquisição do vapor, como mesmo se prontificava a adquiri-lo por meios próprios, caso fosse necessário, e fazia um inquérito sobre o quanto precisaria gastar com esta aquisição. José Vieira Couto de Magalhães utilizava-se de argumentos diferenciados para sensibilizar interlocutores diferentes, o que fazia em nome dos interesses que julgava vitais para a província sob sua administração. Este não seria, aliás, o único ponto no qual se valeria desta estratégia. Em correspondência com o ministro da Marinha, onde se propunha a realizar os mesmos cálculos apresentados à administração paraense sobre as vantagens econômicas para Goiás do comércio realizado pelo porto de Belém, a economia advinda desta medida saltava para 70\% em relação ao comércio realizado diretamente com o Rio de Janeiro. ${ }^{44}$ Como visto acima, a Francisco Carlos de Araújo Brusque o presidente goiano sentenciou que esta cifra seria de apenas 30\%.

Apesar dos apelos ao governo central, o vapor requisitado não foi concedido, e Magalhães teve de encomendá-lo com recursos provinciais enquanto esteve à frente da administração do Grão-Pará. Esta medida não foi, entretanto, suficiente para resolver a questão, uma vez que foram encontradas dificuldades para desmontá-lo e levá-lo às águas do Araguaia.

A comunicação entre as províncias do Grão-Pará e de Goiás por via fluvial só seria alcançada em 1866, através de um contrato com Florentino Marianno do Amaral que, mediante subvenção concedida pela Assembléia Legislativa paraense de um conto e quatrocentos mil réis, se prontificou a estabelecer a linha de vapores. Em 26 de março ele saiu de Belém coman- 
Relatório apresentado á Assembléia Geral Legislativa na primeira sessão da décima terceira legislatura, pelo ministro e secretário de Estado dos negócios da Agricultura, Comércio e Obras Públicas, Manoel Pinto de Souza Dantas, 22 de maio de 1867, p.204-205.
Recebido para publicação em janeiro de 2009 Aprovado em março de 2009 dando um carregamento de mil e setecentas arrobas de sal, em um barco tripulado por trinta pessoas, chegando à capital goiana em 23 de outubro. Uma vez estabelecida regularmente a linha, esperava-se que o tempo de viagem diminuisse de sete para três meses ${ }^{45}$. José Vieira Couto de MagaIhães conseguia, finalmente, ver as águas do Araguaia e do Tocantins sulcadas regularmente por barcos a vapor. Os recursos para atingir este objetivo não vieram do governo do Rio de Janeiro, mas sim da administração de Belém. 0 governo provincial, mais uma vez, atendia com recursos próprios a uma necessidade à qual o governo imperial não quis ou não pôde dar maior atenção que a necessária para noticiar o fato em seu relatório anual.

\section{Considerações finais}

Embora não tivesse a mesma auto-suficiência das unidades federativas dos Estados Unidos, ideal de regime político liberal na segunda metade do século XIX, nem por isso a província do Grão-Pará estava completamente subjugada por um regime de centralização absoluta, como defendiam os políticos liberais brasileiros do mesmo período. A documentação sobre 0 estabelecimento da navegação a vapor nos rios do norte do país mostra como em diversos momentos as administrações desta província tiveram condições de, com recursos próprios, contratar um serviço mais conforme aos seus interesses, quase sempre em complemento às medidas emanadas do Rio de Janeiro.

Isso não significa, evidentemente, que estas administrações possuiam completa liberdade de ação, até porque esta possibilidade era vedada pela Constituição de 1824. Mas evidencia a existência de uma margem de manobra considerável, habilmente utilizada por administradores empenhados em alcançar soluções para problemas que, muitas vezes, não recebiam do governo central a atenção que imaginavam ser devida. Mesmo que essa margem fosse reduzida, como no caso da província de Goiás, desprovida de portos externos e, portanto, sem condições de arrecadar com a principal fonte de renda do Império, ela ainda assim subsistia e era utilizada, ainda que sob a forma de estratégias discursivas destinadas a sensibilizar 0 governo imperial mediante a apresentação de uma situação possivelmente mais grave do que a real.

Á luz destes elementos, torna-se oportuno questionar sobre a validade dos modelos teóricos que buscam explicar o sistema político imperial como sendo baseado em uma centralização quase absoluta do poder, tendente a sufocar as províncias através da privação de recursos que as impedia de atender às suas mais urgentes necessidades. 0 estabelecimento de linhas de vapores complementares á operada pela Companhia de Navegação e Comércio do Amazonas, bem como a introdução de uma linha regular mantida pelos cofres paraenses nos rios Araguaia e Tocantins mostram que essa centralização, ainda que presente no tocante a alguns elementos da administração imperial, não pode ser tomada como onipresente em toda a extensão e em todos os momentos da história do Brasil Império. São medidas que indicam, ao invés disso, a existência de um regime de tipo federativo no pais, como primeiro indicou Miriam Dolhnikoff em seu livro citado no início deste trabalho. 